\title{
Histopathological and electron microscopic studies of lymphangiectasia of the small intestine in Behçet's disease
}

\author{
HITOSHI ASAKURA, AKIRA MORITA, TETSUO MORISHITA, MASAHARU \\ TSUCHIYA, YOONOSUKE WATANABE, AND YASUHIRO ENOMOTO \\ From the Departments of Internal Medicine and Pathology, School of Medicine, Keio University, \\ Tokyo, Japan
}

SUMMARY The gastrointestinal involvement and immunological findings in 16 patients with Behçet's disease are described. Four of 15 biopsy specimens of jejunal mucosa showed marked lymphangiectasia in the lamina propria similar to the appearance which was thought to be a characteristic finding in protein-losing enteropathy. None of the patients had hypoproteinaemia. Increases in serum immunoglobulin IgA were proved in six of 15 cases; in IgM, five of 15; and in IgG, one of 15. Electron microscopic studies showed that there were thousands of precipitated lymph protein bodies in the extracellular spaces of the lamina propria. Ulcers and healed ulcers of the large intestine were studied by light microscopy.

Behçet (1937) described a chronic, relapsing complex of oral ulceration, genital ulceration, and ocular inflammation. It has been recognized that many other systems may be involved, including the skin, cardiovascular, central nervous, and gastrointestinal systems, and the joints, together with venous thrombosis (Enoch, 1969; Mason and Barnes, 1969; Mowat and Hothersall, 1969); Francis, 1970; Kalbian and Challis, 1970; Haim, Barzilai, and Hazani, 1971). Thus, the findings may vary greatly from the triad originally described. Some authors consider Behçet's disease a general systemic disease affecting visceral organs on a wide scale, and the literature has been extensively reviewed (Francis, 1970; O'Duffy, Carney, and Deodhar, 1971). Despite the many theories put forward the aetiology remains unknown. Histological changes are not specific and no diagnostic test is available.

Bøe, Dalgaard, and Scott (1958) described several cases of a mucocutaneous-ocular syndrome with intestinal involvement and said that involvement of the gastrointestinal tract also was not infrequent. Behçet's disease, which was associated with necrotizing oesophagitis, ulcers of the oesophagus, stomach, jejunum, ileum, or large bowel, or segmental ileitis has been reported (Bechgaard, 1940; Jensen, 1944; Ramsay, 1967; Empey, 1972). However,

Received for publication 13 December 1972. no case of Behçet's disease associated with lymphangiectasia of the small intestine has been reported. In this paper we draw attention to lymphangiectasia of the small intestine in Behçet's disease and discuss the mechanism of lymphangiectasia of the lamina propria in the small intestine, which has been considered to be a characteristic finding of proteinlosing enteropathy.

\section{Materials and Methods}

All cases of Behçet's disease were observed in Japanese patients during the period from 1967 to 1972 at the Keio University Hospital. The diagnosis of Behçet's disease was based on the following criteria: (1) a history of recurrent oral ulcers; (2) a history of recurrent genital ulcers; and (3) uveitis and/or iritis. Twelve patients fulfilled all three criteria. Other four cases met two criteria and skin lesions or arthralgia. The sex distribution was 13 males and three females, a ratio of $4 \cdot 3$ to 1 . The age of the patients ranged from 22 to 55 years.

Biopsy specimens were obtained under fluoroscopy using the peroral intestinal biopsy technique of Crosby and Kugler. Each subject was fasted overnight (more than 15 hours) before biopsy. After the biopsy instrument was triggered in the jejunal portion under fluoroscopic control it was withdrawn as 
rapidly as possible. Specimens obtained from patients were fixed in neutral buffered $10 \%$ formalin within one to three minutes. The specimens were embedded in paraffin and stained with a haematoxylin and eosin. Some of the specimens were placed in icecold $1 \%$ osmium tetroxide buffered with $0.1 \mathrm{M}$ sodium bicarbonate. Specimens were cut into $1 \mathrm{~mm}$ thick slices with a sharp razor blade. After fixation, the specimens were dehydrated and embedded in epoxy resin. Thin sections were stained with aqueous uranyl acetate and lead solution, and photographs were taken with an Hitachi HS 8 electron microscope.

Serum immunoglobulin levels were measured by the antibody agar diffusion method, using reagents provided by Behringwerke (West Germany).

\section{Results}

Clinical features of patients with Behçet's disease are summarized in table $I$. Twelve of 16 patients fulfilled all three criteria. Eight patients had manifestations of gastrointestinal involvement.

Radiographs of the small intestine were taken (table II). Thickening of folds and fragmentation or stippling was observed in more than half of the cases of Behçet's disease. Only one case was associated with multiple ulcers of the ileal and colonic segments. Figures 1 and 2 show thickening of folds of the jejunal segment and the features of enteritis. These findings were seen in the jejunum as well as in the ileum.

The histological aspects of the jejunal mucosa in

\begin{tabular}{|c|c|c|c|c|c|c|c|c|c|}
\hline Case & Age & Sex & $\begin{array}{l}\text { Recurrent } \\
\text { Oral } \\
\text { Ulceration }\end{array}$ & $\begin{array}{l}\text { Recurrent } \\
\text { Genital } \\
\text { Ulceration }\end{array}$ & $\begin{array}{l}\text { Ocular } \\
\text { Inflammation } \\
\text { (uveitis, } \\
\text { hypopyon) }\end{array}$ & $\begin{array}{l}\text { Cutaneous } \\
\text { Lesions }\end{array}$ & $\begin{array}{l}\text { Arthralgia, } \\
\text { Arthritis }\end{array}$ & $\begin{array}{l}\text { Central } \\
\text { Nervous } \\
\text { System } \\
\text { Involvement }\end{array}$ & $\begin{array}{l}\text { Gastro- } \\
\text { intestinal } \\
\text { Involvement }\end{array}$ \\
\hline I.H. & 24 & $\mathbf{m}$ & + & + & - & + & - & - & + \\
\hline H.S. & 41 & $\mathbf{f}$ & + & + & + & + & + & - & + \\
\hline K.T. & 41 & $\mathbf{m}$ & + & - & + & + & + & - & - \\
\hline Y.K. & 38 & $\mathbf{m}$ & + & + & + & + & - & - & + \\
\hline H.C. & 48 & $\mathbf{m}$ & + & + & + & + & + & - & + \\
\hline Y.I. & 22 & $\mathbf{m}$ & + & + & + & + & + & + & - \\
\hline H.K. & 23 & $\mathbf{m}$ & + & + & + & + & + & - & - \\
\hline A.I. & 32 & $\mathbf{m}$ & + & + & + & + & + & - & + \\
\hline M.O. & 33 & f & + & - & + & + & + & - & + \\
\hline H.F. & 26 & $\mathbf{m}$ & + & + & + & + & + & - & - \\
\hline H.U. & 25 & $\mathbf{m}$ & + & + & + & + & - & - & + \\
\hline S.M. & 35 & $\mathbf{m}$ & + & + & + & - & - & - & - \\
\hline H.M. & 55 & $\mathbf{m}$ & + & + & + & + & - & - & - \\
\hline S.I. & 28 & $\mathbf{m}$ & + & + & + & + & - & - & + \\
\hline
\end{tabular}

Table I Clinical features of patients with Behçet's disease

\begin{tabular}{|c|c|c|c|c|c|c|c|c|c|c|c|}
\hline Case & Age & $\operatorname{Sex}$ & $\begin{array}{l}\text { Thickening } \\
\text { of Folds }\end{array}$ & Segmentation & Fragmentation & Stippling & $\begin{array}{l}\text { Hyper- } \\
\text { secretion }\end{array}$ & Dilatation & $\begin{array}{l}\text { Moulage } \\
\text { Sign }\end{array}$ & Ulcers & Stenosis \\
\hline I.H. & 24 & m & - & - & - & + & - & - & - & - & - \\
\hline K.T. & 41 & $\mathbf{m}$ & + & - & - & + & - & + & - & - & - \\
\hline Y.K. & 38 & $\mathbf{m}$ & + & - & - & - & - & - & - & - & - \\
\hline H.C. & 48 & $\mathbf{m}$ & + & - & ++ & - & - & - & - & - & - \\
\hline Y.I. & 22 & $\mathbf{m}$ & + & - & - & + & - & - & - & - & - \\
\hline A.I. & 32 & $\mathrm{~m}$ & - & + & + & ++ & - & - & - & - & - \\
\hline M.O. & 33 & f & - & - & + & - & - & - & - & - & - \\
\hline H.F. & 26 & m & - & - & + & + & - & - & - & - & - \\
\hline H.U. & 25 & m & + & + & + & + & - & - & - & - & - \\
\hline S.M. & 35 & $\mathbf{m}$ & $+t$ & - & - & + & - & - & - & - & - \\
\hline H.M. & 55 & $\mathbf{m}$ & ++ & + & ++ & ++ & ++ & - & + & - & - \\
\hline H.N. & 30 & $\mathbf{m}$ & - & - & - & + & - & - & - & - & - \\
\hline Y.I. & 31 & f & - & - & - & + & - & - & - & - & - \\
\hline S.I. & 28 & $\mathrm{~m}$ & ++ & - & ++ & - & ++ & ++ & - & + & - \\
\hline
\end{tabular}

Table II $X$-ray findings of the small intestine in Behçet's disease

- = absent $\quad+$ - present $\quad++=$ marked 


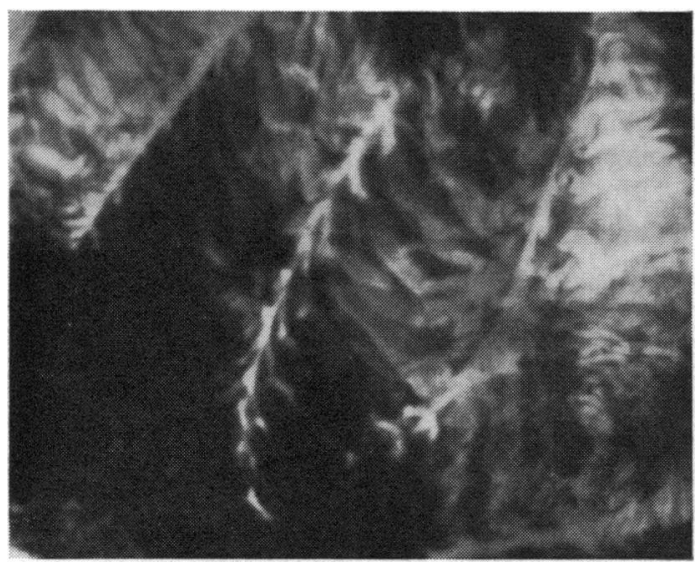

Fig. 1

Fig. 1 Radiograph of the small intestine. Thickening of the jejunal folds can be seen.

Fig. 2 Segmentation, fragmentation, and hypersecretion in a radiograph of the small intestine are shown.

cases of Behçet's disease are summarized in table III. No atrophic villi were seen. Vacuolated changes of the epithelial cells were seen in a patient who had marked manifestations of enteritis.Villi were divided into three groups: finger-like villi, leaf-like villi, and clubbed, finger-shaped villi. Clubbed finger-shaped villi were observed in villi which had markedly

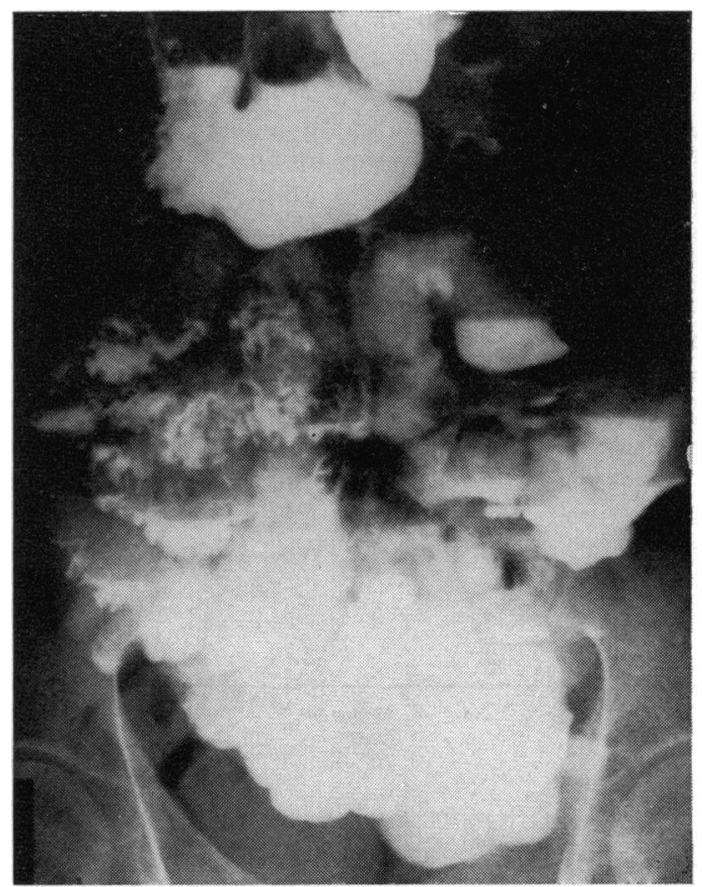

Fig. 2

dilated lymphatic vessels and oedema in the lamina propria of the mucosa (fig. 3). Infiltration of small round cells in the lamina propria of the jejunal mucosa was seen in all cases. Most of the cases had oedema in the lamina propria and/or the submucosa of the jejunal mucosa. It was stressed that marked lymphangiectasia in the lamina propria of the mucosa,

\begin{tabular}{|c|c|c|c|c|c|c|c|c|}
\hline \multirow[t]{2}{*}{ Case } & \multirow[t]{2}{*}{ Height of Villi } & \multirow[t]{2}{*}{ Shapes of Villi } & \multirow{2}{*}{$\begin{array}{l}\text { Degenerative } \\
\text { Changes of } \\
\text { Epithelium }\end{array}$} & \multirow[t]{2}{*}{ Goblet Cells } & \multirow{2}{*}{$\begin{array}{l}\text { Infiltration of } \\
\text { Small Round } \\
\text { Cells }\end{array}$} & \multicolumn{2}{|l|}{ Oedema } & \multirow[t]{2}{*}{ Lymphangiectasia } \\
\hline & & & & & & Lamina Propria & Submucosa & \\
\hline I.H. & $\mathbf{N}$ & $\mathbf{F}$ & Absent & $\mathbf{N}$ & +++ & + & + & + \\
\hline H.S. & $\mathbf{N}$ & $\mathbf{F}$ & Absent & $\mathbf{N}$ & $++t$ & + & ++ & ++ \\
\hline K.T. & $\mathrm{N}$ & F & Absent & increased & ++ & + & + & + \\
\hline Y.K. & $\mathbf{N}$ & $\mathbf{F}$ & Absent & increased & ++ & ++ & + & + \\
\hline H.C. & $\mathbf{N}$ & $\mathbf{F}$ & Absent & $\mathbf{N}$ & + & + & + & + \\
\hline Y.I. & $\mathbf{N}$ & C.F. & Absent & $\mathbf{N}$ & ++ & ++ & ++ & + \\
\hline H.K. & $\mathbf{N}$ & $\mathbf{F}$ & Absent & $\mathbf{N}$ & ++ & ++ & ++ & + \\
\hline A.I. & $\mathbf{N}$ & $\mathbf{F}$ & Absent & $\mathbf{N}$ & ++ & ++ & + & + \\
\hline M.O. & $\mathbf{N}$ & C.F & Absent & $\mathbf{N}$ & ++ & +++ & $+t$ & $+t+$ \\
\hline H.F. & $\mathbf{N}$ & & Absent & $\mathbf{N}$ & $+t+$ & + & + & + \\
\hline H.U. & $\mathbf{N}$ & C, F, L & Vacuolated & & ++ & +++ & $+t+$ & +++ \\
\hline S.M. & $\mathbf{N}$ & & Absent & increased & ++ & ++ & + & +++ \\
\hline H.M. & $\mathbf{N}$ & $\mathbf{F}$ & Absent & $\mathbf{N}$ & +++ & + & + & + \\
\hline H.N. & $\mathbf{N}$ & & Absent & $\mathbf{N}$ & ++ & $+t$ & + & ++ \\
\hline Y.I. & $\mathbf{N}$ & F,L & Absent & $\mathbf{N}$ & ++ & ++ & ++ & +++ \\
\hline
\end{tabular}

Table III Histological aspect of the jejunal mucosa in Behçet's disease

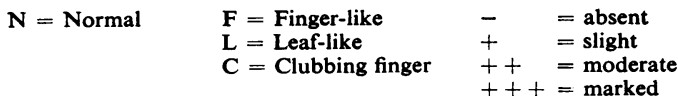

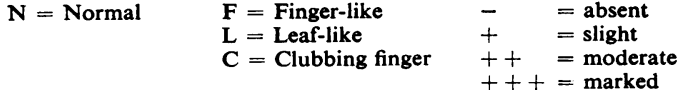




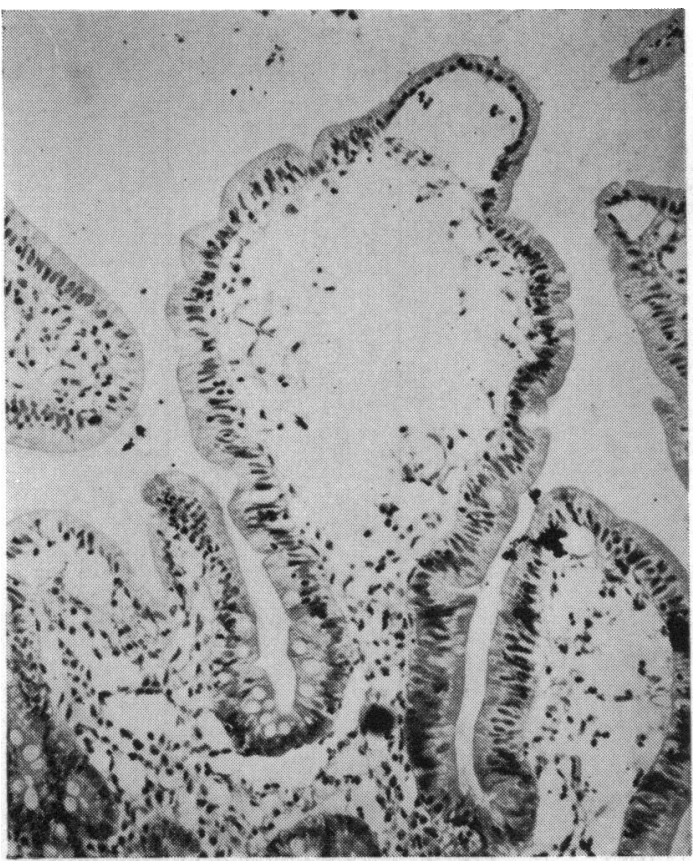

Fig. 3 Clubbing, finger-like villi of the jejunal mucosa. Lymphangiectasia and oedema in the lamina propria are seen. ( $H$ and $E \times 170)$.

Fig. 4 Villi of a case of Behcet's disease (left) and of a case of lymphangiectasia (right). There was no morphological difference between these villi. $(H \& E \times 170)$.

Fig. 3
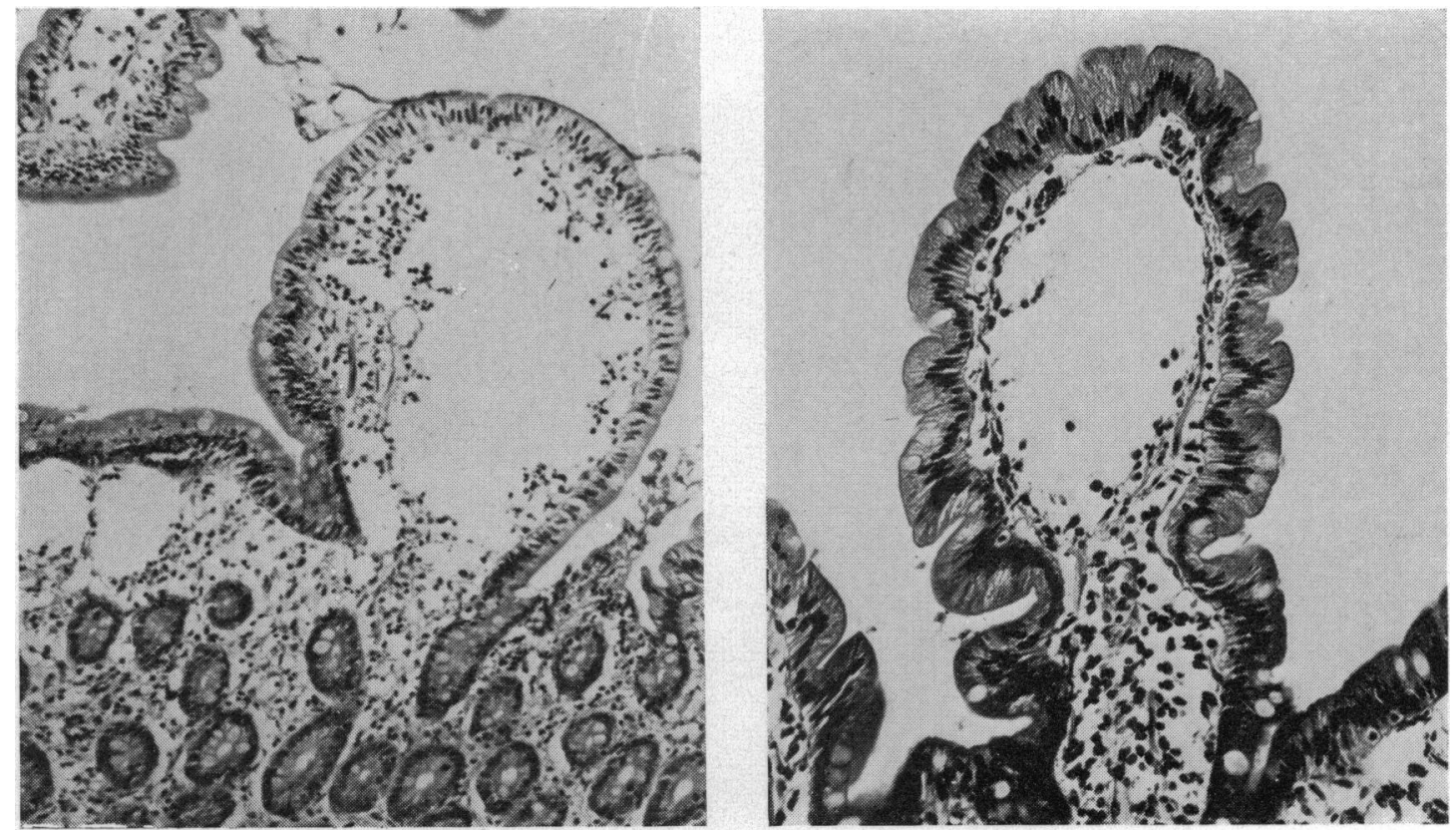

Fig. 4 

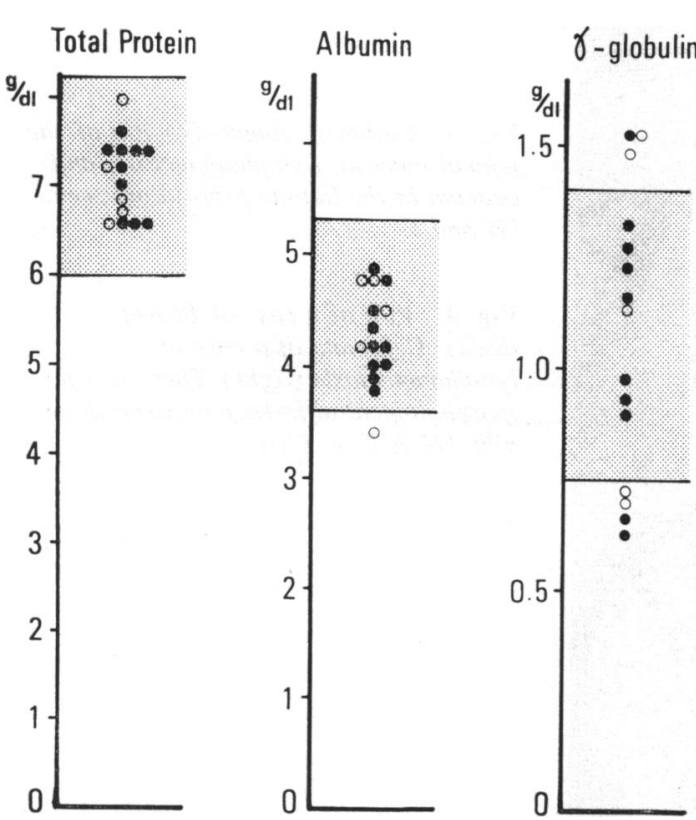

Fig. 5 Serum proteins in Behçet's disease. $\bigcirc$ Cases associated with lymphangiectasia of small intestine; - cases without lymphangiectasia.
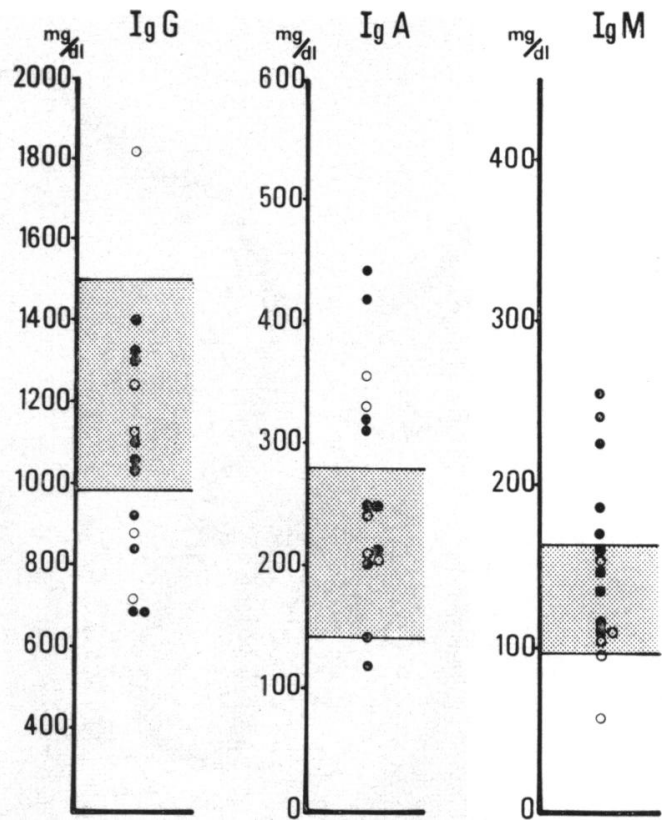

Fig. 6 Serum immunoglobulins in Behçet's disease. $\bigcirc$ Cases associated with lymphangiectasia of small intestine; cases without lymphangiectasia.

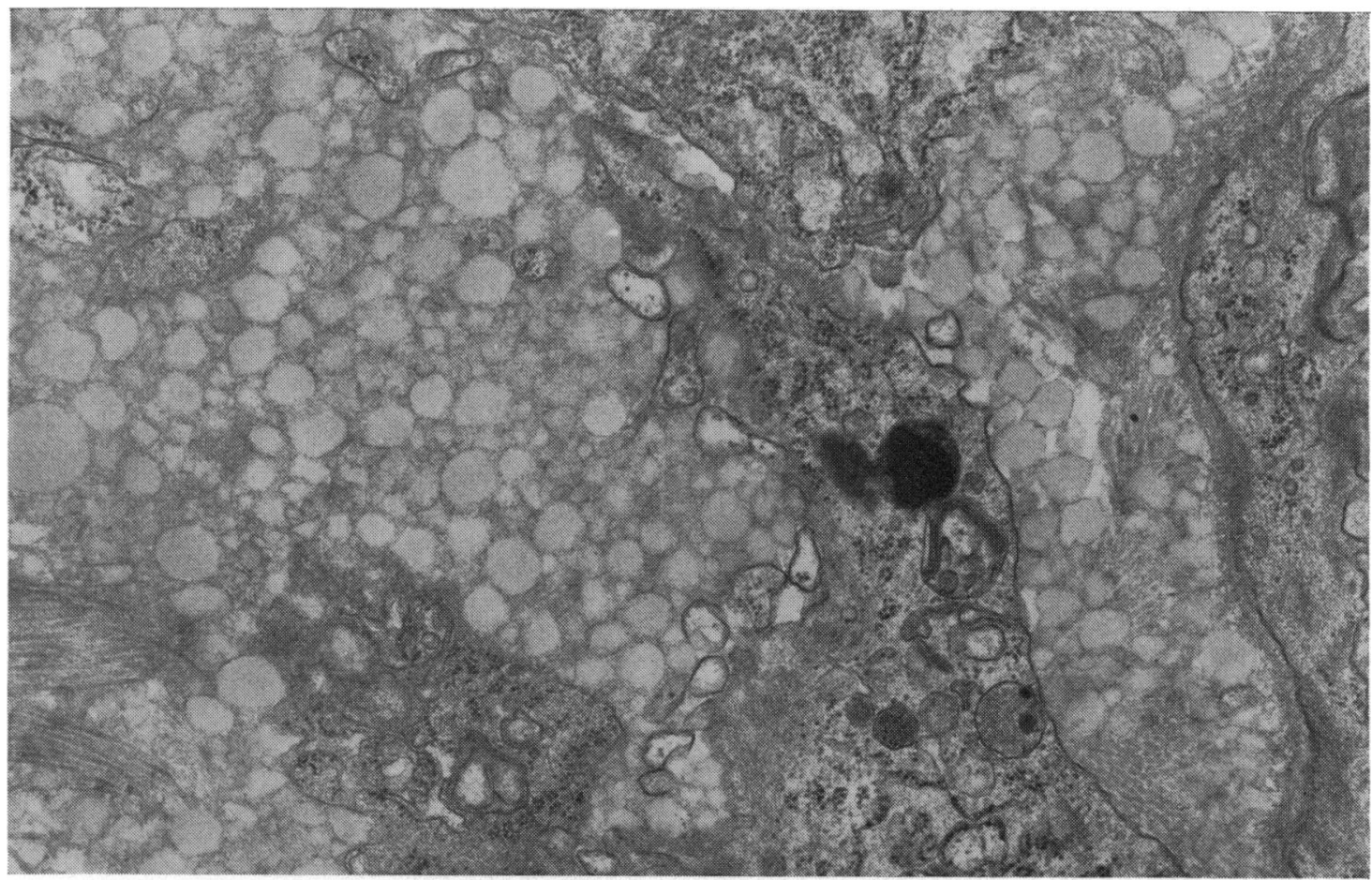

Fig. 7 Globular bodies in the extracellular spaces of the lamina propria $(\times 27000)$. 
which was thought to be a characteristic finding of protein-losing enteropathy, was observed in four of 15 cases with Behçet's disease (fig. 4). However, total serum protein levels of patients with Behçet's disease were all within normal limits and serum albumin levels were in normal ranges in all but one case (fig. 5). Levels of serum IgG were decreased in six cases but serum IgA was elevated in six cases. No decrease in serum levels of $\operatorname{IgA}$ and $\operatorname{IgM}$ was observed except one case (fig. 6).

Out of three cases examined with the electron microscope, a peculiar change was found in one case. In this case there were thousands of globular bodies in the extracellular spaces of the lamina propria (fig. 7) and of the basal part of the epithelium. These bodies varied considerably in diameter, ranging from 80 to $400 \mathrm{~m}_{\mu}$. They consisted of a homogeneous substance of low density and had no limiting membrane. The morphology of these globules indicated that they are precipitated lipoprotein-like substance. This case had moderate oedema in the lamina propria of the jejunal mucosa seen on light microscopy.

There were multiple ulcers and healed ulcers in the ileum and colon of one case with Behçet's disease. The ulcers were not deep. The ulcerated area had granulations beneath with infiltration of small round cells but no giant cells or granuloma (figs. 8, 9).

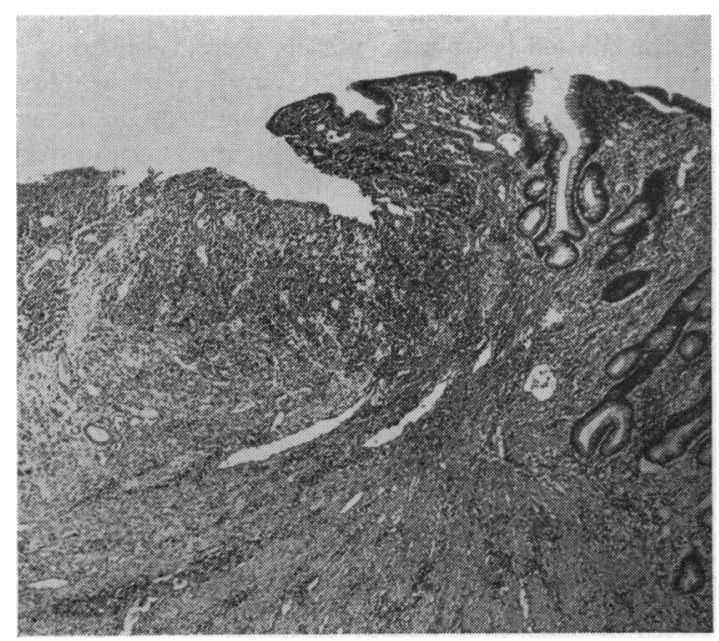

Fig. 8

\section{Discussion}

Waldmann, Steinfeld, Dutcher, Davidson, and Gordon (1961) reported a group of patients with idiopathic hypoproteinaemia secondary to excessive loss of serum protein into the gastrointestinal tract and demonstrated marked lymphatic dilatation in intestinal biopsies from these patients. He focused on a disturbance of the intestinal lymph system to explain the enteric albumin loss, and called this disease 'intestinal lymphangiectasia', a term which is now firmly established in the clinical literature. Lymphangiectasia of the lamina propria of the small intestine has been thought to be a characteristic finding of protein-losing enteropathy. Intestinal lymphangiectasia has been characterized by generalized disorders of the lymphatic channels, including dilated lymphatic vessels of the mucosa of the intestine and excessive enteric loss of plasma proteins. Other important features include hypocalcaemia, lymphoedema, chyluria, chylothorax, chylous ascites, and lymphocytopenia (McDonagh, Gueft, Pyun, and Arias, 1965; Mistilis and Skyring, 1966). The biopsy specimens obtained from cases of intestinal lymphangiectasia revealed that dilated lymphatic vessels could be seen both in the villi and in the submucosa. It is thought that there are congenital or acquired disorders of lymphatics in these patients with an obstruction to outflow resulting in increased

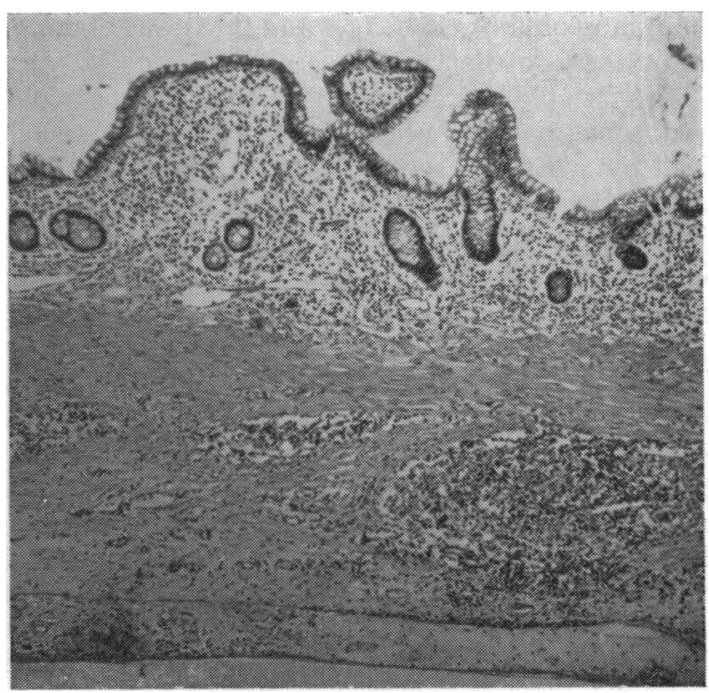

Fig. 9

Fig. 8 Ulcer of the colon in a case of Behçet's disease. $(H \& E \times 50)$.

Fig. 9 Healed ulcer of the colon in a case of Behçet's disease. The muscle layer is covered with regenerated epithelium. $(H \& E \times 50)$. 
hydrostatic pressure and lymphatic dilatation distal to the obstruction (Pomerantz and Waldmann, 1963). Whether the dilated lymphatic vessels are merely part of more widespread lymphatic vessel changes and due to an intrinsic structural defect in the vessel wall or secondary to a functional or mechanical block of the intestinal lymphatics is not clear (Mistilis, Skyring, and Stephen, 1965), and the mechanism of the excessive enteric loss of serum protein in this disease is not fully understood. Dilated abdominal lymphatic vessels were reported in a patient with constrictive pericarditis, a disorder known to produce enteric loss of serum protein.

A biopsy study of the jejunal specimens obtained from 72 patients who were suffering from various diseases showed that those patients in whom the lymphatic vessels in the lamina propria were markedly dilated consisted of those who were suffering from intestinal lymphangiectasia, hepatic cirrhosis with ascites, or Behçet's disease (Tsuchiya, Asakura, Morita, and Morishita, 1973).

Levels of total protein, albumin, and $\gamma$-globulin in the serum of cases with intestinal lymphangiectasia or constrictive pericarditis were markedly reduced. The serum revealed a very low concentration of each immunoglobulin (IgG, IgA, and IgM) in cases of intestinal lymphangiectasia determined by a radial immunodiffusion method (Strober, Wochner, Carbone, and Waldmann, 1967; Asakura, Morita, and Tsuchiya, 1972; Tsuchiya and Asakura, 1972). However, no decrease in levels of serum albumin and immunoglobulins (IgG, IgA and IgM) was observed in our cases of Behçet's disease.

Behçet (1937) described a mucocutaneous-ocular syndrome that now bears his name and is characterized by a triad of symptoms-recurrent oral ulceration, recurrent genital ulceration, and ocular inflammation. There are various other minor cutaneous (pyodermas), neurological (neuro-Behçet), gastrointestinal, vascular (thrombophlebitis), and joint manifestations associated with this disease. The aetiology of Behçet's disease has long been disputed. Behçet himself suggested a viral hypothesis on the basis of finding inclusion bodies in scrapings from the ulcers. Thrombophlebitis and erythema nodosum are frequent features of this disease, and it has been considered that the aetiology may have a vascular or allergic basis. An autoimmune basis for Behçet's disease is perhaps the most widely accepted hypothesis at the present time, since autoantibodies against oral mucosa have been found in the serum of these patients and the serum levels of these antibodies fluctuate with the severity of the disease (Shimizu, Katsuta, and Oshima, 1963 ; Lehner, 1967; Cooper, Penny, and Fiddes, 1971; Lehner, 1972). And thymic abnormalities clarified by Tsuchiya and
Yoshimatsu (1972) may add great interest to the hypothesis of an autoimmune mechanism.

Diseases involving the gastrointestinal tract are often be associated with skin lesions. Ulcerative colitis, gastrointestinal polyposis, and some malabsorption syndromes are examples of these. Jensen (1944) was the first to recognize the association of Behçet's disease and disease of the bowel when he described ulcerative colitis occurring in two patients who were known to have Behcet's disease. Other cases of colitis as a manifestation of Behçet's disease have been described by Bechgaard (1940), Bøe et al (1958), and Ramsay (1967). The occurrence of gastrointestinal symptoms in patients with Behçet's disease has been described by Oshima, Shimizu, Yokohara, Matsumo, Kano, Kagami, and Nagaya (1963), reporting the clinical features of 85 patients with Behçet's disease. They found that $40 \%$ had symptoms such as diarrhoea, nausea, or abdominal pain, and one case had proved jejunal ulceration.

Our biopsy study suggested that gastrointestinal symptoms were due to non-specific enteritis and oedema and lymphangiectasia of the intestinal mucosa as well as the intestinal ulcers. Factors which affected dilatation of the lymphatic vessels were unknown. Dilated lymphatic vessels in the lamina propria of intestinal mucosa were seen in hepatic cirrhosis as well as in intestinal lymphangiectasia (Astaldi and Strosselli, 1960). It was observed in a case of intestinal lymphangiectasia described by Dobbins (1966) that substances which were contained in the dilated lymphatic vessels were thousands of chylomicrons and precipitated lymph proteins. However, the facts explaining enteric loss of protein were not shown in his study. An electron microscopic study on intestinal biopsy specimens obtained from a patient with Behçet's disease showed that thousands of lipoprotein-like substances were seen in the extracellular spaces of the lamina propria in the jejunal mucosa, and were similar to those of intestinal lymphangiectasia. Unfortunately, lymphangiography was not performed in cases of Behcet's disease. It will be disputed whether this lymphatic dilatation is either due to an obstruction to outflow or excessive formation of lymphatic fluids owing to vascular hyperpermeability. These abnormalities of the lymphatic channels might occur secondarily to immunological disorders.

We are grateful to Dr Shozo Baba, Instructor in the Department of Surgery of Keio University Hospital, for cooperation in resecting the ulcerated loops.

\section{References}

Asakura, H., Morita, A., and Tsuchiya, M. (1972). Clinical usefulness 
of serum albumin and $\gamma$-globulin tracer studies in digestive diseases. Gastroenterologia jap., 7, 33-43.

Astaldi, G., and Strosselli, E. (1960). Peroral biopsy of the intestinal mucosa in hepatic cirrhosis. Amer. J. dig. Dis., n.s., 5, 603-612.

Bechgaard, P. (1940). Case of recurrent aphthous stomatitis accompanied by conjunctivitis and ulcerations of genitals and skin (Danish). Ugeskr. Laeg., 102, 1019-1023.

Behçet, H. (1937). Úber rezidivierende, aphtöse, durch ein Virus verursachte Geschwüre am Mund, am Auge und an den Genitalien. Derm. Wschr., 105, 1152-1157.

Bøe, J., Dalgaard, J. B., and Scott, D. (1958). Mucocutaneous-ocular syndrome with intestinal involvement. Amer. J. Med., 25, 857-867.

Cooper, D., Penny, R., and Fiddes, P. (1971). Autologous-plasma sensitization in Behcet's disease. Lancet, 1, 910.

Dobbins, W. O. (1966). Electron microscopic study of the intestinal mucosa in intestinal lymphangiectasia. Gastroenterology, 51, 1004-1017.

Empey, D. W. (1972). Rectal and colonic ulceration in Behçet's disease. Brit. J. Surg., 59, 173-175.

Enoch, B. A. (1969). Gangrene in Behçet's syndrome. Brit. med. J., 3, 54.

Francis, T. C. (1970). Recurrent aphthous stomatitis and Behçet's disease. Oral Surg., 30, 476-487.

Haim, S., Barzilai, D., and Hazani, E. (1971). Involvement of veins in Behçet's syndrome. Brit. J. Derm., 84, 238-241.

Jensen, J. S. (1944). Ulcerous hemorrhagic colitis associated with Behçet's syndrome (Danish). Ugeskr. Laeg., 106, 176-179.

Kalbian, V. V., and Challis, M. T. (1970). Behçet's disease. Report of twelve cases with three manifesting as papilledema. Amer. $J$. Med., 49, 823-829.

Lehner, T. (1967). Behçet's syndrome and autoimmunity. Brit. med.J., $1,465-467$.

Lehner, T. (1972). Immunologic aspects of recurrent oral ulcers. Oral Surg., 33, 80-85.

McDonagh, T. J., Gueft, B., Pyun, K., and Arias, I. M. (1965). Hypoproteinemia, chylous ascites, steatorrhea, and protein-losing enteropathy due to chronic inflammatory obstruction of major intestinal lymph vessels. Gastroenterology, 48, 642-647.
Mason, R. M., and Barnes, C. G. (1969). Behçet's syndrome with arthritis. Ann. rheum. Dis., 28, 95-103.

Mistilis, S. P., and Skyring, A. P. (1966). Intestinal lymphangiectasia. Therapeutic effect of lymph venous anastomosis. Amer. J. Med., 40, 634-641.

Mistilis, S. P., Skyring, A. P., and Stephen, D. D. (1965). Intestinal lymphangiectasia: mechanism of enteric loss of plasmaprotein and fat. Lancet, 1, 77-80.

Mowat, A. G., and Hothersall, T. E. (1969). Gangrene in Behçet's syndrome. Brit. Med. J., 2, 636.

O'Duffy, J. D., Carney, J. A., and Deodhar, S. (1971). Behçet's disease. Report of 10 cases, 3 with new manifestations. Ann. intern. Med., 75, 561-570.

Oshima, Y., Shimizu, T., Yokohara, R., Matsumoto, T., Kano, K., Kagami, T., and Nagaya, H. (1963). Clinical studies on Behcet's syndrome. Ann. rheum. Dis., 22, 36-45.

Pomerantz, M., and Waldmann, T. A. (1963). Systemic lymphatic abnormalities associated with gastrointestinal protein loss secondary to intestinal lymphangiectasia. Gastroenterology, 45, 703-711.

Ramsay, C. A. (1967). Behçet's syndrome with large bowel involvement. Proc. roy. Soc. Med., 60, 185-186.

Shimizu, T., Katsuta, Y., and Oshima, Y. (1963). Immunological studies on Behçet's syndrome. Ann. rheum. Dis., 24, 494-500.

Strober, W., Wochner, R. D., Carbone, P. P., and Waldmann, T. A. (1967). Intestinal lymphangiectasia: a protein-losing enteropathy with hypogammaglobulinemia, and impaired homograf rejection. J. clin. Invest., 46, 1643-1656.

Tsuchiya, M., and Asakura, H. (1972). Comparative studies of two cases of protein-losing enteropathy associated with non-specific ulcers of the ileum. Gastroenterologia jap., 6, 27-36.

Tsuchiya, M., Asakura, H., Morita, A., and Morishita, T. (1973), Lymphangiectasia of the small intestine. 7th Congr. Microcir. 1-6. (To be published).

Tsuchiya, M., and Yoshimatsu, H. (1972). The thymus. Clinical prospect of thymology. Keio J. Med., 21, 1-4.

Waldmann, T. A., Steinfeld, J. L., Dutcher, T. F., Davidson, J. D. and Gordon, R. S., Jr., (1961). The role of the gastrointestinal system in idiopathic hypoproteinemia. Gastroenterology, 41, 197-207. 